FORMATION Formation emploi

Revue française de sciences sociales

151 | juillet-septembre

L'enseignement agricole, un chantier d'avenir

\title{
Edito : Le secteur agricole : un exemple à cultiver?
}

Jean-Frédéric Vergnies

\section{OpenEdition}

Journals

Édition électronique

URL : https://journals.openedition.org/formationemploi/8378

DOI : 10.4000/formationemploi.8378

ISSN : 2107-0946

\section{Éditeur}

La Documentation française

\section{Édition imprimée}

Date de publication : 1 novembre 2020

Pagination : 1-2

ISSN : 0759-6340

\section{Référence électronique}

Jean-Frédéric Vergnies, «Edito : Le secteur agricole : un exemple à cultiver? », Formation emploi [En ligne], 151 | juillet-septembre, mis en ligne le 01 novembre 2020, consulté le 08 janvier 2022. URL http://journals.openedition.org/formationemploi/8378 ; DOI : https://doi.org/10.4000/ formationemploi.8378 


\title{
Le secteur agricole : un exemple à cultiver?
}

\author{
Jean-Frédéric Vergnie \\ Rédacteur en chef
}

L'agriculture occupe aujourd'hui une part très minoritaire de l'activité. Pour autant, c'est un domaine au cour des activités essentielles, comme nous le rappelle la crise issue de la Covid 19. La singularité de la formation dans ce domaine découle à la fois d'une réflexion globale sur l'organisation productive du secteur et se traduit par une organisation originale de la formation.

La formation, depuis son origine, poursuit explicitement une triple fonction, comme le rappelle Francois Purseigle dans sa postface : fonction tout d'abord politique, car visant à promouvoir un groupe social, fonction productive ensuite, destinée à favoriser les mutations d'un secteur agricole appelé à se moderniser, fonction sociale enfin, pour permettre aux familles rurales de bénéficier de l'effort global de scolarisation.

À l'heure où l'on s'interroge sur la place et le rôle des entreprises, et où les conséquences de la "responsabilité sociale des entreprises (RSE) » reste en grande partie programmatique, le secteur agricole pourrait être un exemple de "bonnes pratiques » en termes de relations formation-emploi, à considérer avec attention. En effet, on envisage clairement ici de faire évoluer conjointement le système productif (Grenelle de l'environnement, loi d'avenir " produire autrement »...) et le système éducatif (plan « enseigner à produire autrement »...).

Et ce d'autant plus que les recherches en la matière sont peu nombreuses. Le dossier 57 de notre revue soulignait l'originalité de l'enseignement agricole dans les années 90. Depuis, avec les orientations de la politique agricole vers l'agroécologie, les conceptions à la fois de la production et de la formation ont amorcé une orientation vers un nouveau paradigme (Cf. le dossier de Formation Emploi « L'économie verte : rupture ou adaptation de la formation et de l'emploi ", $\mathrm{n}^{\circ} 135$, de 2016). 
Le présent dossier précise certaines des spécificités intéressantes du domaine agricole. Ainsi, dans un article à orientation historique, Fabien Knittel et Adeline Divoux-Bonvalot montrent comment les écoles ménagères agricoles ont contribué à l'évolution du rôle des femmes en milieu rural, et à l'organisation des modèles productifs. Pourtant, les rôles productifs restent encore fortement sexués, comme le révèle Christine Fontanini dans le cas des vétérinaires. Si la profession atteint la parité quantitative, les femmes et les hommes se dirigent vers des modes d'exercice différents.

L'enseignement agricole fait face aux inégalités sociales de manière originale. À l'instar des maisons familiales et rurales, qui dispensent des formations en alternance, devenues un lieu de remédiation scolaire où le rôle des agents d'encadrement a fortement évolué, comme le met en exergue ici Joachim Benet Rivière.

Enfin, les deux derniers articles montrent, chacun à leur manière, certaines innovations introduites suite au mot d'ordre " enseigner et produire autrement ». Ainsi, Youri Meignan et Claire Masson analysent comment l'injonction à l'autonomisation des élèves, devenue une référence essentielle des processus éducatifs, peut être mise en œuvre. Enfin, Loïc Mazenc et Cécile Gazo étudient la place du référentiel professionnel des diplômes dans l'évolution de l'enseignement agricole, en lien avec la transformation du monde agricole. Les rénovations de référentiel ne suffisent pas à assurer le rapprochement entre formation et évolution des métiers tant les pratiques agricoles changent. Enseigner l'agroécologie peut impliquer une «sortie de cadre " par rapport aux référentiels, quitte à rompre avec les schémas pédagogiques classiques.

Bonne lecture. 